\title{
Strengthening National Health Priorities for Diabetes Prevention and Management
}

To the Editors:

In his report in the October 2017 issue of MEDICC Review, Vega-Jiménez stressed that the design and integration of a prediabetes (intermediate hyperglycemia) registry would serve as an essential prevention strategy to improve population health outcomes in Cuba.[1] Cuba's universal health system, with its robust health workforce and established primary care services from family doctor-and-nurse offices, polyclinics and hospitals, is well prepared for this ambitious step forward in prevention and management of non-communicable diseases (NCD) like diabetes.

In the Dominican Republic (DR), a neighboring Caribbean nation of almost 11 million residents, the prevalence of type 2 diabetes is a growing concern, with 2016 prevalence estimated at $9.3 \%$ (7.8\% in men; $10.6 \%$ in women), and all-age attributable mortality at $4 \%$.[2] Reported risk factors were overweight (54.8\%), obesity (23\%) and physical inactivity (35\%).[2] One recent study by the National Institute of Diabetes, Endocrinology, and Nutrition and Iberoamerican University, with a national sample of 10,500 adults, reported that $13.5 \%$ had type 2 diabetes, and $9.3 \%$ had prediabetes.[3] Although DR health leaders tout a national diabetes registry and strategic plan to combat diabetes and reduce sedentary behaviors, no national guidelines are available, and appropriate referral practices for diabetes management are inconsistently utilized.[2]

To combat rising diabetes prevalence, national health systems such as the DR's should consider a twofold approach that targets reduction of risk factors such as prediabetes and hypertension. First, a national advisory board can develop a consensus for evidence-based national guidelines that support clinical decision- making and best practices. Second, strengthened links between primary care and specialized health centers can facilitate patient management and referral measures for additional medical services. This approach would complement the Pan American Health Organization's 2012 Passport to Healthy Lifestyle initiative, which provided personal logbooks for patients diagnosed with diabetes and other NCDs.

Extensive connections between primary care and specialized health programs are essential to promote paradigm changes that integrate NCD prevention and management approaches for health service delivery. A prediabetes registry and appropriate patient referral measures would be a transcendental step to improving population health outcomes in vulnerable populations across Latin America and the Caribbean. 1 -

1. Vega-Jiménez J. Cuba needs a prediabetes registry now. MEDICC Rev. 2017 Oct;19(4):44.

2. World Health Organization. Perfil de la República Dominicana para la diabetes, 2016 [Internet]. Geneva: World Health Organization; 2018 [cited 2018 Jun 16]. Available from: http://www.who.int/diabetes/country-profiles/ dom_es.pdf. Spanish.

3. Acento [Internet]. Santo Domingo: Acento; c2018. Actualidad. El 13.45\% de la población padece diabetes según estudio; 2018 [cited 2018 Aug 25]. Available from: https://acento.com.do/2018/actualidad/8558818-13-45-la-poblacion-pa dece-diabetes-segun-estudio/. Spanish.

Bienvenido A. Veras-Estévez MD MPH (bienvenido.veras@ gmail.com), Department of Epidemiology, José María Cabral y Báez Regional University Hospital, Santiago de los Caballeros, Dominican Republic.

Helena J. Chapman MD MPH PhD, AAAS Science and Technology Policy Fellow, National Aeronautics and Space Administration, Washington, DC. 